\title{
Elevated plasma levels of TNF-alpha and Interleukin-6 in patients with diastolic dysfunction and glucose metabolism disorders Wilfried Dinh ${ }^{\dagger 1,2}$, Reiner Füth ${ }^{\dagger 1,2}$, Werner Nickl1,2, Thomas Krahn³, Peter Ellinghaus ${ }^{3}$, Thomas Scheffold ${ }^{2}$, Lars Bansemir ${ }^{1}$, Alexander Bufe ${ }^{1,2}$, Michael Coll Barroso ${ }^{4}$ and Mark Lankisch*1,2
}

\author{
Address: ${ }^{1}$ Helios Clinics Wuppertal, Heart Center, Germany, ${ }^{2}$ Institute for Heart and Circulation Research, University Witten/Herdecke, Germany, \\ ${ }^{3}$ Target Discovery, Bayer Schering Pharma, Wuppertal, Germany and ${ }^{4}$ CoroVital, Institute of Sports Cardiology and Science, Wuppertal, Germany \\ Email: Wilfried Dinh - wilfried.dinh@helios-kliniken.de; Reiner Füth - reiner.fueth@helios-kliniken.de; Werner Nickl - werner.nickl@helios- \\ kliniken.de; Thomas Krahn - thomas.krahn@bayer-healthcare.com; Peter Ellinghaus - peter.ellinghaus@helios-kliniken.de; \\ Thomas Scheffold - th.scheffold@t-online.de; Lars Bansemir - lars.bansemir@helios-kliniken.de; Alexander Bufe - alexander.bufe@helios- \\ kliniken.de; Michael Coll Barroso - ISAH@t-online.de; Mark Lankisch* - mark.lankisch@helios-kliniken.de \\ * Corresponding author †Equal contributors
}

Published: 12 November 2009

Cardiovascular Diabetology 2009, 8:58 doi:10.1 186/1475-2840-8-58

This article is available from: http://www.cardiab.com/content/8/l/58

(C) 2009 Dinh et al; licensee BioMed Central Ltd.

This is an Open Access article distributed under the terms of the Creative Commons Attribution License (http://creativecommons.org/licenses/by/2.0), which permits unrestricted use, distribution, and reproduction in any medium, provided the original work is properly cited.
Received: 8 October 2009

Accepted: 12 November 2009

\begin{abstract}
Background: Diabetes mellitus (DM) has reached epidemic proportions and is an important risk factor for heart failure (HF). Left ventricular diastolic dysfunction (LVDD) is recognized as the earliest manifestation of DM-induced LV dysfunction, but its pathophysiology remains incompletely understood. We sought to evaluate the relationship between proinflammatory cytokine levels (TNF-alpha, IL-6) and tissue Doppler derived indices of LVDD in patients with stable coronary artery disease.

Methods: We enrolled $4 \mathrm{I}$ consecutive patients (mean age 65+/-10 years) submitted for coronary angiography. Echocardiographic assessment was performed in all patients. Pulsed tissue Doppler imaging was performed at the mitral annulus and was characterized by the diastolic early relaxation velocity Em. Conventional transmitral flow was measured with pw-doppler. Early $(E)$ transmitral flow velocity was measured. LVDD was defined as E/Em ratio $\geq 15, \mathrm{E} / \mathrm{Em}$ 8-14 was classified as borderline. Plasma levels of TNF-alpha and IL-6 were determined in all patients. A standardized oral glucose tolerance test was performed in subjects without diabetes.

Results: Patients with E/Em ratio $\geq 15$, classified as LVDD and those with E/Em ratio 8-I4 (classified as borderline) had significantly higher IL-6 $(P=0,00 \mathrm{I})$, TNF-alpha $(P<0,00 \mathrm{I})$ and NT-pro- BNP $(P=0,00 \mathrm{I})$ plasma levels compared to those with normal diastolic function. TNF-alpha and IL-6 levels remains significantly elevated after adjustment for sex, age, left ventricular ejection function, body mass index, coronary heart disease, smoking, hypertension and diabetes mellitus with linear regression analysis. Furthermore, in subjects LVDD or borderline LV diastolic function, $75 \%$ had diabetes or IGT, respectively. When subjects without diabetes were excluded, both IL-6 $(P=0,006)$ and TNF-alpha $(P=0,002)$ remained significantly elevated in subjects with $\mathrm{E} / \mathrm{Em}$ ratio $\geq 15$.
\end{abstract}

Conclusion: This study reveals that increased plasma levels of IL-6 and TNF-alpha were associated with LVDD. These findings suggest a link between low-grade inflammation and the presence of LVDD. An active proinflammatory process may be of importance in the pathogenesis of diastolic dysfunction. 


\section{Background}

Diastolic heart failure and diabetes mellitus (DM) are contributors to mortality, hospitalization and medical costs in health care systems worldwide. Cardiovascular disease is the leading course of death among subjects with diabetes, accounting for over $60 \%$ of mortality. While DM is uniformly recognized as an important risk factor for the development of coronary artery disease and its complications, it is less well acknowledged that DM is a powerful and independent risk factor for the development and prognosis of heart failure independent of coronary artery disease (CAD) [1]. Left ventricular diastolic dysfunction (LVDD) is considered a precursor of systolic heart failure and diabetic cardiomyopathy $[2,3]$ and is common in the community and especially in diabetic patients $[4,5]$.

There is increasing evidence that inflammation is involved in the pathophysiology of heart failure and diabetes [6-9]. Most recent studies have linked insulin- resistance with TNF- $\alpha$ and IL6 and those studies have shown that a measure of proinflammation is predictive for type 2 diabetes. Furthermore, increased circulating concentrations of IL- 6 and TNF- $\alpha$ were found in Type 2 DM and impaired glucose tolerance [10-12].

Little information is available about whether inflammation is involved in the development of LVDD as the earliest stage in the development of heart failure.

Advantages in echocardiographic techniques have made it possible to comprehensively access LV diastolic function [13]. Tissue Doppler imaging is a simple, reproducible and widely available noninvasive tool for the assessment of alterations of left ventricular (LV) diastolic function. A recent guideline of the American Society of Echocardiography (ASE) implemented TDI techniques as the basic principle to diagnose diastolic heart failure [14].

This study was designed to explore the possible association between LVDD and proinflammation reflected by IL6 and TNF- $\alpha$ levels in subjects with stable coronary artery disease.

\section{Methods}

The present study is a substudy of a larger survey in which we investigated the relationship between diastolic dysfunction and cardiovascular autonomic neuropathy in 150 patients submitted for coronary angiography.

41 subjects submitted for coronary angiography for stable or suspected coronary artery disease (CAD) were consecutively enrolled in this substudy. The protocol was approved by the local ethics committee, and signed informed consent was obtained from all patients. We excluded patients with hypertrophic obstructive cardio- myopathy, moderate-to-severe valvular disease, uncontrolled hypertension, atrial fibrillation or other severe arrhythmias. Oral glucose tolerance tests (OGTTs) were carried out according to the World Health Organization protocol as previously described. Echocardiography for the diagnosis of diastolic dysfunction was performed on a Philips IE33 Ultrasound System machine. Conventional transmitral flow was measured with pw-doppler. Early (E), atrial (A) transmitral peak flow velocities and the ratio (E/A) were measured. Pulsed wave TDI was performed at the junction of the LV wall with the medial mitral annulus end-expiratory. Early diastolic velocity (Em) was recorded. Ratio of E/Em was calculated. The E/ Em ratio was used to classify LVDD. LVDD was defined as $\mathrm{E} / \mathrm{Em}$ ratio $\geq 15$, borderline diastolic function as $\mathrm{E} / \mathrm{Em}$ between 8-14 and normal diastolic function as $\mathrm{E} / \mathrm{Em}<8$ according to the guidelines of the ASE [14].

Interleukin- 6 and TNF- $\alpha$ were measured with high-sensitivity enzyme linked immunoassay [14]. NT-pro BNP was measured by a commercial available Immuno-Assay (Roche Diagnostics ${ }^{\circledR}$ ).

Autonomic nervous function was assessed according to the guidelines of German diabetes association. Spectral analysis with Fourier transformation was performed. Therefore a commercially computer program (VariaCardio TF4-System) was used. The following tests were performed: (1) coefficient of variation of R-R intervals at rest, (2) spectral power in the very-low-frequency band, (3) spectral power in the LF band, (4) HRV during deep breathing, (5) maximum/minimum 30:15 ratio, (6) valsalva ratio, (7) postural change in systolic blood pressure. CAN is defined as the presence of $\geq 3$ abnormalities among these 7 parameters.

\section{Statistical analysis}

All analyses were performed using SPSS statistical software (SPSS 17.0, Chicago, IL). The data are presented as mean + - SD unless otherwise specified. A $p$ value $\leq 0.05$ was considered statistically significant. Comparison among the 2 groups of subjects for various parameters was performed by 1-way analysis of variance (ANOVA or ttest) when appropriate. Pearson's linear correlation coefficients were calculated for pairs of continuous variables, Spearman's correlations coefficient was used when data were not normally distributed. We first analyzed associations without any adjustments and then with adjustments for potential confounders by multiple linear regression for continuous and logistic regression for categorical variables. 


\section{Results}

\section{Demographics and clinical variables}

The demographic variables of subjects with normal, borderline and increased E/Em ratio are shown in Figure 1. Subjects with E/Em > 15 were significantly older with a higher prevalence of DM. The prevalence of coronary heart disease, systolic dysfunction and hypertension as possible confounders contributing to diastolic dysfunction was similar between the groups.

\section{Glucose tolerance test}

In subjects without DM, an oGTT was performed. 21 (29\%) of patients enrolled in the study had a history of diabetes. The oGTT showed impaired fasting glucose (IGT) or new detected Diabetes (NDM) in 32 (63\%) of the included patients, only 11 (27\%) of subjects enrolled in the study had normal glucose metabolism (NGT). In subjects with $\mathrm{E} / \mathrm{Em}$ ratio $\geq 15$, no patient was found with NGT. $16,7 \%$ had IGT or NDM and $66,7 \%$ known diabetes, respectively. Fasting glucose was $111 \mathrm{mg} / \mathrm{dl}$ in subjects with $\mathrm{E} / \mathrm{Em}$ ratio $\geq 15 \mathrm{vs} .92 \mathrm{mg} / \mathrm{dl}$ and $90 \mathrm{mg} / \mathrm{dl}$ in those with borderline or normal $\mathrm{E} / \mathrm{Em}$ ratio $(\mathrm{P}=0,1)$, whereas HbA1c was $6,9 \%, 6,2 \%$ and $6,1 \%$, respectively $(P=0,3)$.

\section{Proinflammatory cytokines and LVDD}

The mean Em velocity was $8,4 \mathrm{~cm} / \mathrm{s}$ in subjects with $\mathrm{E} / \mathrm{Em}$ ratio $<8,7,0 \mathrm{~cm} / \mathrm{s}$ in those with $\mathrm{E} / \mathrm{Em}$ ratio 8-15 and 5,3 $\mathrm{cm} / \mathrm{s}$ in those with $\mathrm{E} / \mathrm{Em}$ ratio $\geq 15$, respectively.

E/Em ratio was positively correlated with TNF- $\alpha$ levels ( $r$ $=0,34, \mathrm{P}=0,05$, Spearman-Test). In the post-hoc analysis, patients with E/Em ratio > 15, classified as LVDD, had significantly higher IL-6 (7,9 pg/ml vs. 3,4 pg/ml; P = 0,001), TNF- $\alpha(7,2 \mathrm{pg} / \mathrm{ml}$ vs. $3,1 \mathrm{pg} / \mathrm{ml} \mathrm{P}<0,001)$ compared to those with normal diastolic function $(\mathrm{E} / \mathrm{Em}<8$; figure 2and 3). There was no statistically significant difference between the borderline group and those with normal diastolic dysfunction $(\mathrm{P}>0,5)$. TNF- $\alpha(\mathrm{B}=1,7, \mathrm{P}=0,01)$ and IL- $6(\mathrm{~B}=1,51 ; \mathrm{P}=0,04)$ levels remains significantly elevated after adjustment for sex, age, left ventricular ejection function, body mass index, coronary heart disease, smoking, hypertension and diabetes mellitus with linear regression analysis. When subjects without diabetes were excluded, both IL-6 $(\mathrm{P}=0,006)$ and TNF-alpha $(\mathrm{P}=$ 0,002 ) remained significantly elevated in subjects with $\mathrm{E} /$ Em ratio $\geq 15$.

\begin{tabular}{|c|c|c|c|c|}
\hline & $\mathrm{E} / \mathrm{Em}<8$ & $\mathrm{E} / \mathrm{Em} 8-14$ & $\mathrm{E} / \mathrm{Em} \geq 15$ & Overall $\mathrm{P}$ \\
\hline $\mathrm{n}$ & $12(29 \%)$ & $23(56 \%)$ & $6(15 \%)$ & - \\
\hline $\operatorname{Sex}(f)(\%)$ & $8 \%$ & $35 \%$ & $50 \%$ & $0,01 *$ \\
\hline Age (years, mean) & 52 & 55 & 67 & $0,01 *$ \\
\hline BMI $\left(\mathrm{kg} / \mathrm{m}^{2}\right)$ & 30 & 28 & 30 & 0,24 \\
\hline Waist circumference (mean, $\mathrm{cm}$ ) & 105 & 101 & 102 & 0,66 \\
\hline Abdominal girth (mean, $\mathrm{cm}$ ) & 107 & 101 & 100 & 0,34 \\
\hline Fasting glucose (mg/dl) & 92 & 90 & 111 & 0,1 \\
\hline $\mathrm{HbA1c}(\%)$ & $6,1 \%$ & $6,2 \%$ & $6,9 \%$ & 0,31 \\
\hline Smoking (\%) & $83 \%$ & $78 \%$ & $67 \%$ & 0,72 \\
\hline Treated Hypertension (\%) & $92 \%$ & $87 \%$ & $100 \%$ & 0,22 \\
\hline CAD $(\%$, stenosis $>50 \%)$ & $92 \%$ & $78 \%$ & $83 \%$ & 0,66 \\
\hline 1 vessel disease $(\% \text {, stenosis }>50 \%)^{\#}$ & $33 \%$ & $30 \%$ & $50 \%$ & 0,45 \\
\hline 2 vessel disease $(\% \text {, stenosis }>50 \%)^{\#}$ & $17 \%$ & $17 \%$ & $0 \%$ & 0,45 \\
\hline 3 vessel disease $(\% \text {, stenosis }>50 \%)^{\#}$ & $41 \%$ & $17 \%$ & $17 \%$ & 0,45 \\
\hline Previous MI (\%) & $58 \%$ & $43 \%$ & $16 \%$ & 0,24 \\
\hline Previous Angioplasty (\%) & $67 \%$ & $38 \%$ & $67 \%$ & 0,21 \\
\hline Aortocoronary bypass (\%) & $0 \%$ & $5 \%$ & $17 \%$ & 0,27 \\
\hline CAN (Score $\geq 3)(\%)$ & $9 \%$ & $17 \%$ & $60 \%$ & 0,05 \\
\hline $\mathrm{EF}(\mathrm{mean}, \%)$ & $64 \%$ & $65 \%$ & $62 \%$ & 0,9 \\
\hline $\mathrm{EF}<55 \%(\%)$ & $25 \%$ & $17 \%$ & $17 \%$ & 0,84 \\
\hline Diabetes $(\%$, known or new detected $)$ & $33 \%$ & $26 \%$ & $83 \%$ & $0,03 *$ \\
\hline
\end{tabular}

\section{Figure I}

Demographics and clinical variables. Demographics and clinical variables plotted against E/Em ratio. CAN $=$ cardiovascular autonomic neuropathy, $\mathrm{BMI}=$ body mass index, $\mathrm{CAD}=$ coronary artery disease, $\mathrm{MI}=$ myocardial infarction, $\mathrm{DM}=\mathrm{Diabetes}$ mellitus. ${ }^{*}=$ significant $(\mathrm{P}<0,05) . \#=$ no history of aortocoronary bypass surgery. 


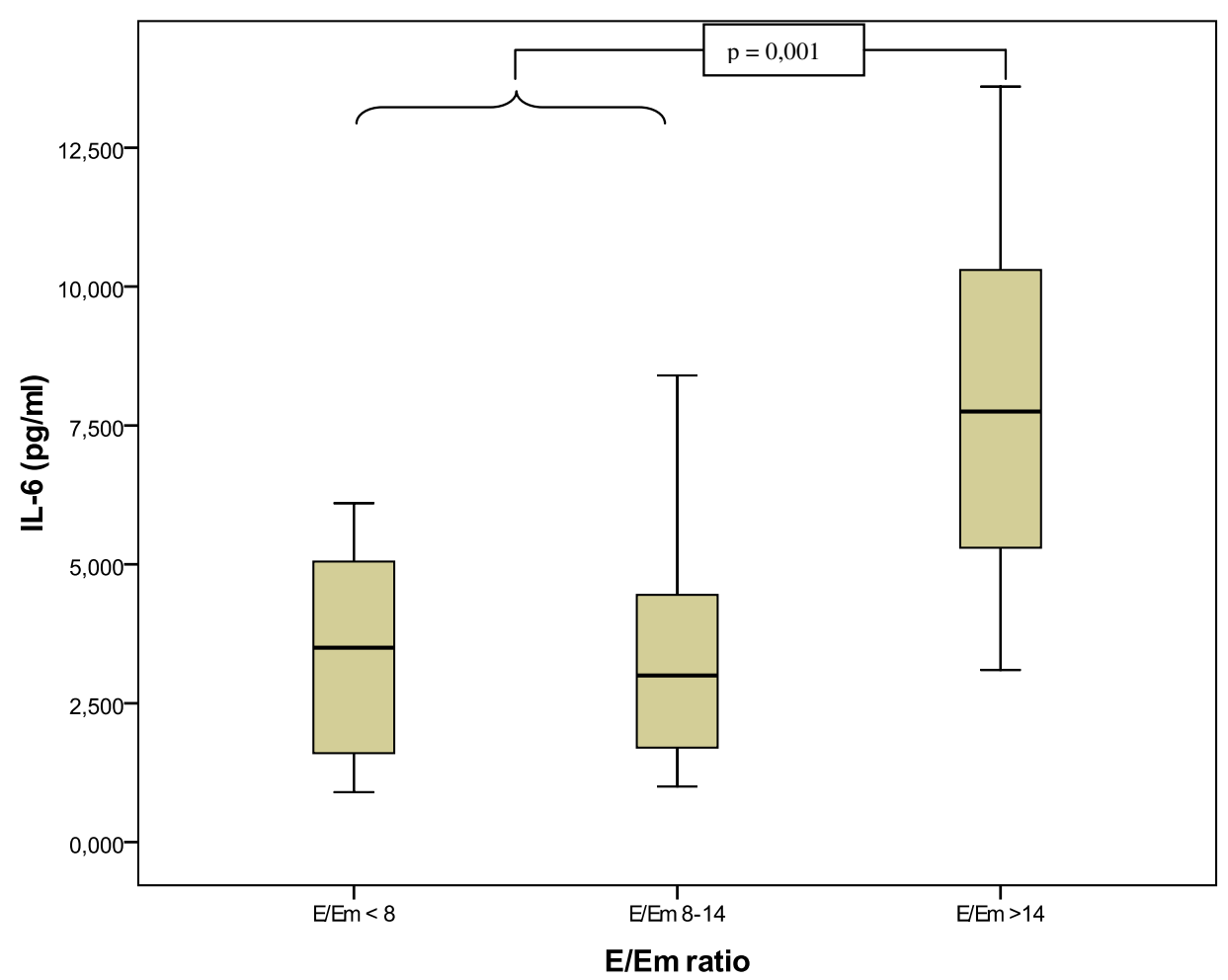

Figure 2

E/Em ratio and IL-6 levels. IL-6 levels are significantly elevated in subjects with LVDD. E = Early mitral inflow velocity, Em = early mitral tissue relaxation velocity.

\section{Cardiovascular autonomic neuropathy (CAN)}

New detected cardiovascular autonomic neuropathy $(\mathrm{CAN}+)$ was found in $22 \%$ of the study group. Although statistically not significant, $60 \%$ of subjects with diastolic dysfunction defined as $\mathrm{E} / \mathrm{Em}$ ratio $\geq 15$ were found $\mathrm{CAN}+$, whereas only $9 \%$ of subjects with normal left ventricular diastolic function were CAN+. In the subgroup with borderline diastolic function, 20\% were diagnosed as CAN+. Of note, in patients CAN+, IL6 levels were significantly higher than in those CAN- $(6,1 \mathrm{pg} / \mathrm{ml}$ vs. $3,7 \mathrm{pg} / \mathrm{ml}, \mathrm{P}=$ $0,42)$. Although statistically not significant, TNF- $\alpha$ levels were also numerical higher $(4,4 \mathrm{pg} / \mathrm{ml}$ vs. $3,5 \mathrm{pg} / \mathrm{ml}, \mathrm{P}=$ $0,42)$.

\section{NT-pro-BNP and LVDD}

NT-pro-BNP levels were significantly higher in those with $\mathrm{E} / \mathrm{Em}$ ratio > 15 compared to those with borderline E/Em ratio or normal diastolic function $(1220 \mathrm{pg} / \mathrm{ml}$ vs. $192 \mathrm{pg} /$ ml vs. $277 \mathrm{pg} / \mathrm{ml}, \mathrm{P}=0.001)$. In diabetics, NT-pro- BNP levels were $608 \mathrm{pg} / \mathrm{ml}$ vs. $229 \mathrm{pg} / \mathrm{ml}$ in non diabetics $(\mathrm{P}=$ $0,06)$.

\section{Discussion}

We were able to demonstrate that LVDD and proinflammatory cytokines are associated in subjects with normal left ventricular systolic function. In particular increased plasma levels TNF- $\alpha$ and IL- 6 seem to be correlated with impaired LVDD and more advanced left ventricular diastolic dysfunction. These data provide clinically important information on systemic immune abnormalities in subjects with LVDD. The Framingham Heart Study was the first to demonstrate an increased risk of heart failure in patients with diabetes [1]. Since then, additional studies, including SOLVD [15] and HOPE [16], have identified diabetes as a major risk factor for the development of heart failure. Conversely, the presence of heart failure was identified as a possible risk factor for diabetes [17]. Several studies have demonstrated evidence for preclinical left ventricular diastolic dysfunction (LVDD) as the first manifestation of myocardial involvement in diabetic patients [3]. Although myocardial changes can be detected with echocardiography, even before the onset of hemodynamic abnormalities in subjects with normal conventional echocardiography, LVDD is often not diagnosed in clinical practice. On the other hand, there is increasing evidence that inflammation is involved in the 


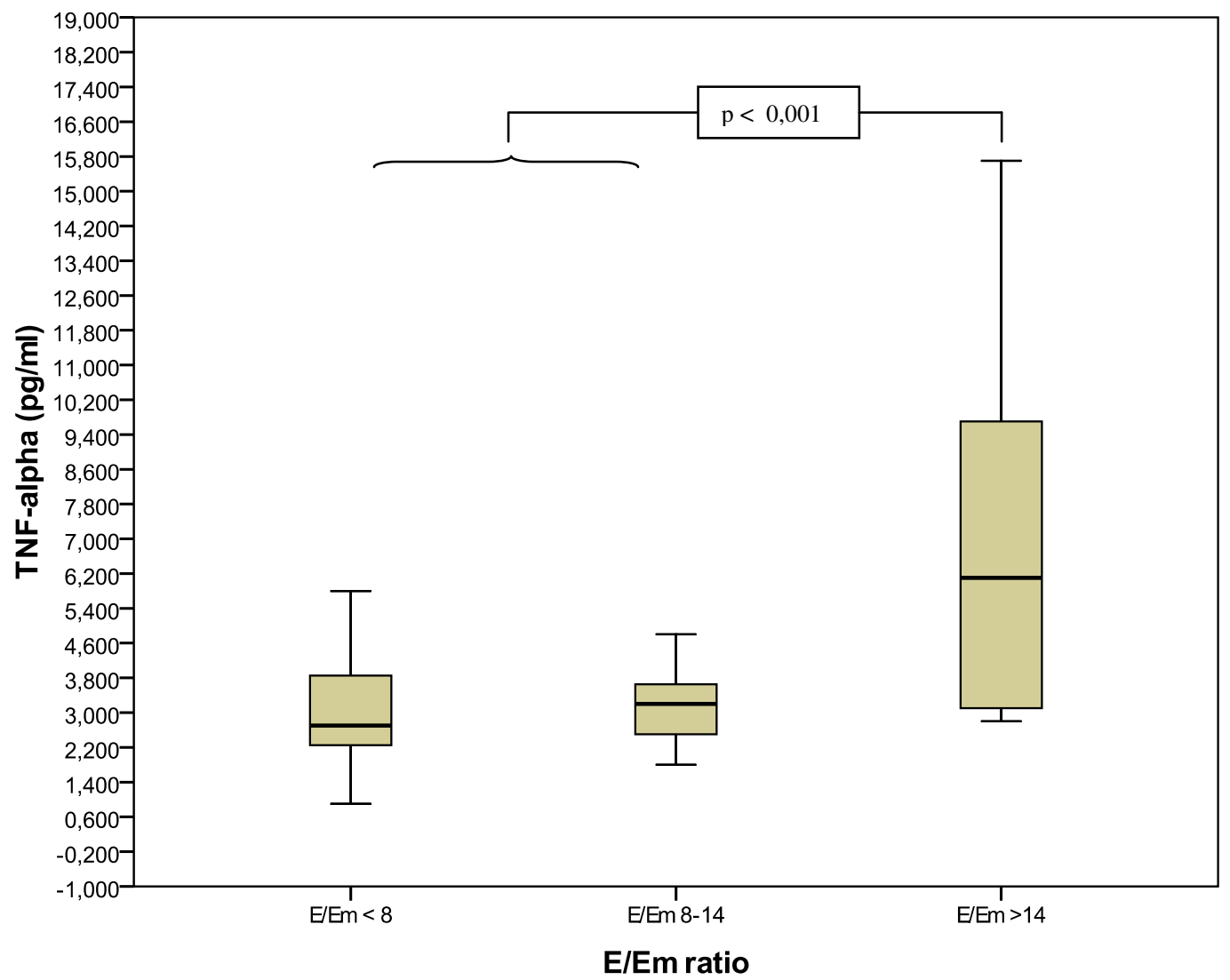

Figure 3

E/Em ratio and TNF- $\alpha$ levels. TNF- $\alpha$ levels are significantly elevated in subjects with LVDD. E = Early mitral inflow velocity, $\mathrm{Em}=$ early mitral tissue relaxation velocity.

pathophysiology of heart failure and diabetes [6-9]. Inflammation has become one of the central themes in the pathogenesis of systolic heart disease over the past decade. So far there have been few data on participation of inflammatory factors in the development of diastolic dysfunction.

It has been demonstrated that IL-6 shows cardiodepressive properties [18]. In patients with systolic heart failure, IL- 6 and TNF- $\alpha$ are associated with functional NYHA class [8]. Furthermore, IL-6 and TNF- $\alpha$ have been shown to be independent predictors of mortality in heart failure [19]. On the other hand, a recent study which followed patients with symptomatic systolic heart failure, E/Em ratio was associated with an increased risk of death or heart transplantation. A E/Em ratio $>17$ had a mortality of approximately $40 \%$ vs. $5 \%$ in those with an E/Em ratio of less than 17 ( $p<0,001)$ [20]. From at al. demonstrated that there is an association between duration of DM and LVDD and that an increasing E/Em ratio is associated with all-cause mortality in diabetic patients [21]. In this study, duration of $\mathrm{DM} \geq 4$ years was correlated with significant LV diastolic dysfunction and LVDD was predictive of allcause mortality independent of hypertension and CAD. Recently Mogelvang et colleagues showed that in the general population, LVDD by TDI is a powerful and independent predictor of death, even in the subgroup with normal conventional echocardiography [22]. Focusing on the elderly subjects, who are prone for diabetes and its complications, diastolic dysfunction is an independent predictor of cardiovascular events [23]. Therefore, we speculate that the association of elevated proinflammatory cytokines with LVDD might put the patients at higher risk for the progression of symptomatic diabetic cardiomyopathy.

Proinflammatory cytokines are capable of modulating cardiovascular function by various mechanisms. It is now known that virtually every nucleated cell type in the myocardium, including the cardiac myocyte, is able to secrete proinflammatory cytokines in response to various myocardial damage or stressors. The expression of these 
cytokines can occur in absence of systemic immune activation.

They partly act in a negative inotropic manner and cause changes in turnover of the extracellular matrix resulting in myocardial fibrosis. The proinflammatory cytokine TNF$\alpha$ induces cardiodepressive effects and causes apoptosis [24]. The development of progressive cardiomyocyte apoptosis plays a critical role on the left ventricular geometry and the adverse cardiac remodeling that occurs in the setting of sustained inflammation.

There are some limitations in the present study. The consensus paper of the ESC [25] deals with the term diastolic heart failure, referring to subjects with heart failure. In our study, diastolic dysfunction was defined in asymptomatic patients using TDI techniques. Nevertheless, TDI is the most sensitive and widely available echocardiographic tool for the assessment of LV diastolic function [14]. Furthermore, the fact that Em- velocity and E/Em are highly correlated with age might impair their predictive abilities in high risk population like ours in which age had an impact on the risk of cardiovascular and diabetes- related complications.

Moreover, we did not measure LA volume index and pulmonary vein velocities. These additional echo data might have been of interest especially in the cohort with E/Em ratio $8-14$.

\section{Conclusion}

Our study shows for the first time, to the best of our knowledge, a relationship between proinflammatory cytokines and abnormalities of diastolic performance in patients without clinical heart failure. The development of diastolic dysfunction and its possible sequelae diabetic cardiomyopathy is likely to be multifactorial, with putative mechanism including metabolic disturbances, insulin resistance, myocardial fibrosis, endothelial dysfunction, autonomic dysfunction and myocyte damage. Proinflammatory cytokines are involved in most if not all of these pathophysiological changes and might be a link between these abnormalities. At present, it is not clear which mechanism can explain the association between diastolic abnormalities and IL- 6 and TNF- $\alpha$-levels. The relationship between LV diastolic performance and the activation of immunoinflammatory system should be studied more thoroughly in the future both on experimental and clinical grounds.

\section{Competing interests}

The authors declare that they have no competing interests.

\section{Authors' contributions}

WD conceived of the study, participated in the study and drafted the manuscript and performed statistical analysis. RF participated in echocardiographic studies and participated in the study design of the study. LB participated in echocardiographic studies. AB participated in echocardiographic study. WN carried out the plasma analysis of IL6, TNF- $\alpha$ and BNP. TK carried out the plasma analysis of IL6, TNF- $\alpha$ and BNP. PE carried out the plasma analysis of IL6, TNF- $\alpha$ and biomarkers. TS participated in the study design of the study and performed statistical analysis. MCB participated in echocardiographic studies. ML participated in the study design and coordination and helped to draft the manuscript. All authors read and approved the final manuscript.

\section{References}

I. Kannel WB, Hjortland M, Castelli WP: Role of diabetes in congestive heart failure: the Framingham study. Am J Cardiol 1974, 34:29-34.

2. Piccini JP, Klein L, Gheorghiade M, Bonow RO: New insights into diastolic heart failure: role of diabetes mellitus. Am J Med 2004, I I6(Suppl 5A):64S-75S.

3. Zabalgoitia M, Ismaeil MF, Anderson L, Maklady FA: Prevalence of diastolic dysfunction in normotensive, asymptomatic patients with well-controlled type 2 diabetes mellitus. Am J Cardiol 200I, 87:320-323.

4. Futh R, Dinh W, Bansemir L, Ziegler G, Bufe A, Wolfertz J, Scheffold $T$, Lankisch M: Newly detected glucose disturbance is associated with a high prevalence of diastolic dysfunction: double risk for the development of heart failure? Acta Diabetol 2009, 46:335-8.

5. Owan TE, Hodge DO, Herges RM, Jacobsen SJ, Roger VL, Redfield MM: Trends in prevalence and outcome of heart failure with preserved ejection fraction. $N$ Engl J Med 2006, 355:25I-259.

6. Kanda T, Takahashi T: Interleukin-6 and cardiovascular diseases. Jpn Heart / 2004, 45: 183-193.

7. Tsutamoto T, Hisanaga T, Wada A, Maeda K, Ohnishi M, Fukai D, Mabuchi N, Sawaki M, Kinoshita M: Interleukin-6 spillover in the peripheral circulation increases with the severity of heart failure, and the high plasma level of interleukin-6 is an important prognostic predictor in patients with congestive heart failure. J Am Coll Cardiol 1998, 31:391-398.

8. Torre-Amione G, Kapadia S, Benedict C, Oral H, Young JB, Mann DL: Proinflammatory cytokine levels in patients with depressed left ventricular ejection fraction: a report from the Studies of Left Ventricular Dysfunction (SOLVD). J Am Coll Cardiol 1996, 27: I20I-I 206.

9. Yudkin JS: Adipose tissue, insulin action and vascular disease: inflammatory signals. Int J Obes Relat Metab Disord 2003, 27(Suppl 3):S25-28.

10. Kado S, Nagase T, Nagata N: Circulating levels of interleukin-6, its soluble receptor and interleukin-6/interleukin-6 receptor complexes in patients with type $\mathbf{2}$ diabetes mellitus. Acta Diabetol 1999, 36:67-72.

II. Muller S, Martin S, Koenig W, Hanifi-Moghaddam P, Rathmann W, Haastert B, Giani G, Illig T, Thorand B, Kolb H: Impaired glucose tolerance is associated with increased serum concentrations of interleukin 6 and co-regulated acute-phase proteins but not TNF-alpha or its receptors. Diabetologia 2002, 45:805-8I2.

12. Pickup JC, Chusney GD, Thomas SM, Burt D: Plasma interleukin6, tumour necrosis factor alpha and blood cytokine production in type 2 diabetes. Life Sci 2000, 67:291-300.

13. Oh JK, Hatle L, Tajik AJ, Little WC: Diastolic heart failure can be diagnosed by comprehensive two-dimensional and Doppler echocardiography. J Am Coll Cardiol 2006, 47:500-506.

14. Nagueh SF, Appleton CP, Gillebert TC, Marino PN, Oh JK, Smiseth OA, Waggoner AD, Flachskampf FA, Pellikka PA, Evangelisa A: Recommendations for the evaluation of left ventricular diastolic 
function by echocardiography. Eur \& Echocardiogr 2009, 10:165-193.

15. Shindler DM, Kostis JB, Yusuf S, Quinones MA, Pitt B, Stewart D, Pinkett T, Ghali JK, Wilson AC: Diabetes mellitus, a predictor of morbidity and mortality in the Studies of Left Ventricular Dysfunction (SOLVD) Trials and Registry. Am J Cardiol 1996, 77:1017-1020

16. Arnold JM, Yusuf S, Young J, Mathew J, Johnstone D, Avezum A, Lonn E, Pogue J, Bosch J: Prevention of Heart Failure in Patients in the Heart Outcomes Prevention Evaluation (HOPE) Study. Circulation 2003, 107:1284-1290.

17. Amato L, Paolisso G, Cacciatore F, Ferrara N, Ferrara P, Canonico S, Varricchio M, Rengo F: Congestive heart failure predicts the development of non-insulin-dependent diabetes mellitus in the elderly. The Osservatorio Geriatrico Regione Campania Group. Diabetes Metab 1997, 23:213-218.

18. Finkel MS, Oddis CV, Jacob TD, Watkins SC, Hattler BG, Simmons RL: Negative inotropic effects of cytokines on the heart mediated by nitric oxide. Science 1992, 257:387-389.

19. Deswal A, Petersen NJ, Feldman AM, Young JB, White BG, Mann DL: Cytokines and cytokine receptors in advanced heart failure: an analysis of the cytokine database from the Vesnarinone trial (VEST). Circulation 200I, 103:2055-2059.

20. Troughton RW, Prior DL, Frampton CM, Nash PJ, Pereira JJ, Martin M, Fogarty A, Morehead AJ, Starling RC, Young JB, et al.: Usefulness of tissue doppler and color M-mode indexes of left ventricular diastolic function in predicting outcomes in systolic left ventricular heart failure (from the ADEPT study). Am J Cardiol 2005, 96:257-262.

21. From AM, Scott CG, Chen HH: Changes in diastolic dysfunction in diabetes mellitus over time. Am J Cardiol 2009, 103:1463-I 466.

22. Mogelvang R, Sogaard P, Pedersen SA, Olsen NT, Marott JL, Schnohr $P$, Goetze JP, Jensen JS: Cardiac dysfunction assessed by echocardiographic tissue Doppler imaging is an independent predictor of mortality in the general population. Circulation 2009, I I 9:2679-2685.

23. Tsang TS, Barnes ME, Gersh BJ, Takemoto Y, Rosales AG, Bailey KR, Seward JB: Prediction of risk for first age-related cardiovascular events in an elderly population: the incremental value of echocardiography. J Am Coll Cardiol 2003, 42: I I 99-I 205.

24. Ing DJ, Zang J, Dzau V], Webster KA, Bishopric NH: Modulation of cytokine-induced cardiac myocyte apoptosis by nitric oxide, Bak, and Bcl-x. Circ Res 1999, 84:21-33.

25. Paulus WJ, Tschope C, Sanderson JE, Rusconi C, Flachskampf FA Rademakers FE, Marino P, Smiseth OA, De Keulenaer G, LeiteMoreira AF, et al:: How to diagnose diastolic heart failure: a consensus statement on the diagnosis of heart failure with normal left ventricular ejection fraction by the Heart Failure and Echocardiography Associations of the European Society of Cardiology. Eur Heart J 2007, 28:2539-2550.

\section{Publish with Bio Med Central and every scientist can read your work free of charge}

"BioMed Central will be the most significant development for disseminating the results of biomedical research in our lifetime. "

Sir Paul Nurse, Cancer Research UK

Your research papers will be:

- available free of charge to the entire biomedical community

- peer reviewed and published immediately upon acceptance

- cited in PubMed and archived on PubMed Central

- yours - you keep the copyright
BioMedcentral 